Agenda, Volume 2, Number 2, 1995, pages 149-158

\title{
Teaching Introductory Economics
}

\author{
Paul Heyne
}

W hen people who have taken introductory economics courses at the college or university level in the United States are asked what they remember about the course, most of them answer that they remember little except that it was boring.

The baleful influence of these benumbing courses has now extended itself to eastern Europe and the former Soviet Union. When Marxian political economy was purged from the curriculum, American-style economics quickly moved in to fill its place. Much of the world, it would seem, is coming to the conclusion that the content of a standard American introductory economics textbook should be part of the knowledge possessed by an educated citizen in any 'capitalist' country. The process has even corrupted the secondary schools, where economics teachers are increasingly expected to anticipate the material their students will encounter in college or university, regardless of whether the students have any intention of taking a higher level economics course or even pursuing a tertiary education.

Australians who have encountered introductory economics at the university level tend more often to look back favourably on their first course, because so many of them enrol initially with the intention of completing a degree in the discipline. By the time they come to reflect on their overall education, they have been socialised to the ways of the economics profession and consequently recall the first course as a challenging but essential first step toward a satisfying career. But conversations with both teaching economists and their former students in New Zealand, Canada, and the United Kingdom persuade me that extensive dissatisfaction with the first course is by no means confined in the English-speaking world to the United States.

\section{The Problem with Introductory Economics}

The problem with the introductory course can be summarised quickly. Its content has evolved on the assumption that everyone enrolling in a first course in economics will eventually go on to earn a specialised degree in the subject, while the degree program itself has been structured on the assumption that everyone who earns a baccalaureate degree in economics will continue to the doctorate. Thus the begin-

Paul Heyne, who teaches introductory economics at the University of Washington in Seattle, USA, warns readers that he earns royalties on sales of a textbook that presents an alternative to the standard academic approach to introductory economics. 
ning student is required to learn concepts and techniques that will be almost wholly useless to anyone who doesn't plan to earn a $\mathrm{PhD}$ in economics. How did such an absurd situation come about and why does it persist, especially in view of the fact that so many college and university economics teachers essentially agree with this analysis?

However it came about, the situation persists basically because academia, despite all its radical talk, is one of the most unrelentingly conservative institutions in society. Colleges and universities derive most of their funding not from customers or clients but from taxpayers and philanthropists who rarely have any clear understanding of what goes on in the ivory towers they support. Undergraduate students, even when given an opportunity to influence the curricula to which they will be subjected, are not altogether sure whether they want education or certification, and insofar as they prefer the latter they are for the most part willing to go along with whatever leads to the coveted degree at a tolerable cost. Because the typical academic institution has no genuine owner and hence no residual claimant, no one in a position to effect constructive changes has the appropriate incentives. Higher-level administrators, who are supposed to have a global perspective, don't want to risk the faculty outrage they would surely encounter if they tried to force changes on departments that have grown comfortable with the status quo.

In economics, the status quo in the introductory course adequately serves the interests of those with the power to control the course's content: teachers, departmental chairpersons or curriculum committees, textbook authors, and textbook publishers. None of this is the product of a conspiracy. We are caught in a kind of prisoners' dilemma, where almost everyone prefers an outcome that is, unfortunately, in no one's interest to bring about. Teachers present what appears in the textbooks, the textbooks offer what the teachers expect, and the teachers expect what has been in the textbooks for as long as they can remember. Paul Samuelson summarised the situation concisely in 1946 when he was trying to predict the lasting impact of Keynes's General Theory upon thinking in the economics profession: 'Finally, and perhaps most important from the long-run standpoint,' he observed, 'the Keynesian analysis has begun to filter down into the elementary textbooks; and, as everybody knows, once an idea gets into these, however bad it may be, it becomes practically immortal' (Samuelson, 1946:189).

Perhaps the best example of a bad idea that has achieved immortality - or possibly an idea that was once good but has grown bad by living too long - is what passes in the textbooks for the theory of the competitive firm. Generations of beginning economics students have dutifully practiced their arithmetic skills by calculating average fixed, average variable, average total, and marginal costs from an arbitrarily constructed schedule of costs and quantities, have plotted these values on a graph, and have learned to say that in the long run under perfectly competitive conditions price will be equal to marginal cost and to average total cost at the latter's lowest point. The unfamiliarity of the terms and the abstract character of the argument make it difficult for most students to comprehend. The instructor consequently can occupy a great deal of class time with explanations and clarifications that 
take no time to prepare. And the ease with which examination questions can be drawn from this material compels all students interested in a good grade to attend faithfully upon the entire performance. None of it, however, finds any subsequent application. The whole system seems to be contrived, as Adam Smith long ago observed about the practices of colleges and universities in general, 'not for the benefit of the students, but for the interest, or more properly speaking, for the ease of the masters' (Smith, 1776;1981:764).

Individual instructors have very limited power to change the situation. Not only will they will have to devise substitute material for whatever standard textbook material they choose to omit. They also risk the criticism of colleagues and even some of their own students for failing to teach material that turns out to be presupposed in the next theory course. Those who are trying to prepare their students for standardised exams have very little freedom to improvise, because the standardised exams sample heavily the examinees' acquaintance with technical concepts and definitions. Maverick teachers may even acquire a reputation for not teaching a 'rigorous' course, in a culture where 'rigour' is the most highly-respected virtue and can best be demonstrated by teaching all the conventional theoretical concepts.

So persistence of the situation despite its widely recognised absurdities should not surprise or puzzle us. The difficult question is how we might change it. To answer that question, we must first think about what we want to accomplish. What ought to be the goal in an introductory economics course?

\section{What Should Introductory Economics Aim to Achieve?}

Except for students who know when they enrol that they want to specialise in economics, the goal should not be to prepare the students for the next theory course. Most of the general students who enrol in the first course will never take a more advanced theory course in economics. Perhaps a larger proportion would go on to take 'intermediate theory' if the first course conveyed more understanding and made less of an attempt to 'cover' everything. That word 'cover' may say more than the teachers who use it intend to say. To cover means to conceat, our goal should be to discover or uncover, not to cover. Most of the students, general or professional, who do choose to take our intermediate theory courses would probably be better prepared for them if their introductory course discovered or uncovered the usefulness of a few basic concepts than if it tried to anticipate a lot of subsequent technicalities. We should teach the first course in economics as if it is the last course students will ever take in the subject.

Our goal should be to provide students with a few tools that they can use to think more clearly and correctly about the complex interactions that make up a commercial society. This was Adam Smith's term for a society in which everyone lives by exchanging and everyone is. consequently a merchant (Smith, 1776;1981:37). The term is much more helpful and descriptive than 'capitalism'. It focuses attention on what most needs explanation: the processes of exchange that must accompany the division of labour that has made us wealthy beyond the dreams of anyone living two centuries or even one century ago. The citizens of a 
democracy ought to understand how a commercial society (or a market economy) works, because such knowledge is a powerful antidote to many of the absurd policy proposals that special interests and thoughtless people press upon their governments.

\section{Scarcity and Exchange}

The standard introductory economics course does too little by way of teaching students how markets work. It attempts, and fails for the most part even in this limited task, to teach students how academic economists work. One reason is that professional economists have become hung up on the concept of scarcily. Most of them, if asked for the fundamental problem with which economics deals, will unhesitatingly answer 'scarcity'. That's not so much wrong as misleading. It's true that if there were no scarcity, we would not have to economise. And so we would probably never have extended the division of labour and would never have developed commercial societies. But the genuinely useful light that economics sheds does not fall on the economising process; it illuminates the process of exchange. Just about everyone knows how to economise, and does so effectively. What people do not know and what economics can explain for them is how millions of economising people, each one pursuing his or her own interest, manage to cooperate effectively despite the fact they are all substantially ignorant of what others want or can do. The fundamental problem of economics is not so much scarcity as a multitude of interdependent projects that somehow have to be coordinated.

Here is a little exercise with which I often introduced economic theory to my students when I was still captive to the scarcity obsession. A student is taking four courses in the current term and he wants to maximise his average grade across the four courses. He has a limited amount of time to study for final exams. He knows exactly by how much additional study will improve his final grade in each of the four courses. The table presents the grades he can count on receiving if he spends the hours indicated on each subject. How many hours should the student spend studying each subject if he has twelve hours to study? How many hours should he spend on each subject if he has only six hours to study?

\begin{tabular}{|c|c|c|c|c|}
\hline $\begin{array}{l}\text { Hours spent } \\
\text { studying }\end{array}$ & \multicolumn{4}{|c|}{ Grade expected in } \\
\hline & Chemistry & Economics & History & Maths \\
\hline 0 & 60 & 40 & 76 & 84 \\
\hline 1 & 75 & 60 & 81 & 88 \\
\hline 2 & 80 & 70 & 85 & 91 \\
\hline 3 & 83 & 75 & 88 & 93 \\
\hline 4 & 85 & 78 & 90 & 94 \\
\hline 5 & 86 & 80 & 91 & 94 \\
\hline
\end{tabular}


I used to ask those questions and let the students play around with the numbers for a while before triumphantly demonstrating that with twelve hours to study, three should be devoted to Chemistry, four to Economics, three to History, and two to Mathematics, because only with this allocation are the gains from the last hour studying each subject equal. For the same reason, with only six hours to study, the student should devote two to Chemistry, three to Economics, one to History, and none at all to Mathematics. I thought that I was capturing my students' interest at the outset of the course by illustrating the applicability of economic theory to all of life. In fact I was suggesting its essential irrelevance.

Students trying to figure out how long to study for their various courses don't know in advance what grades their study will secure for them. They are not constrained to studying in increments of whole hours. They are not single-mindedly interested in maximising their grade-point average. And they obtain no valuable assistance whatsoever in situations like this from knowing the marginal conditions for an optimum. What my exercise demonstrated was that economists have tools that can make simple matters more complicated than they are and complicated matters more simple than they are.

But even if people know how to economise in their private lives without any help from economic theory, do they understand the implications of scarcity for the government sector? Shouldn't economists continue to emphasise the importance of scarcity to citizens who behave as if the public purse has no bottom? It is certainly appropriate for economists to insist, in season and out, that governmentfunded projects also have opportunity costs and to call constant attention to the realities of what must be sacrificed to obtain desired goods. The question is how this can be done most effectively. It will not be by drawing production-possibility curves and extracting marginal rates of transformation, because that radically misstates the problem. Except in a dictatorship, no one economises for society as a whole or for the government sector. In a democracy, public policies emerge from interactions - exchanges! - among optimising parties: citizens, elected and appointed officials, and interest groups of many kinds. When the marginal benefits and the marginal costs accrue to different parties, an optimising model just doesn't fit.

None of this is intended to be a criticism of marginal analysis, but only of its use to illuminate 'problems' that it doesn't actually illuminate. Most of these will be economising or optimising problems that have been drastically oversimplified so that we can 'solve' them, or that postulate an omniscient dictator, or that people typically manage for themselves quite handily without any formal calculations. Nor am I rejecting all presentations of the logic of optimising. I spend a lot of time in my introductory courses dealing with the concepts of marginal cost and marginal revenue and the formal logic of net-revenue maximisation. But I don't do so with the intention of helping business decision makers decide how much to produce or what prices to set, because the bare logic of optimisation really doesn't provide much help with such decisions. I want to use the logic of net-revenue maximisation to explain or illuminate the enormous variety of pricing policies that we regularly observe. My objective is to explain market processes, interpersonal transactions, 
patterns of exchange - which is, I maintain, what introductory economics is mostly good for. It's good for explaining how markets work, which most people do not understand. It is far less useful or illuminating when it tries to explain how individuals optimise.

In The Wealth of Nations, Adam Smith was basically trying to explain how markets work. In order to provide a coherent and persuasive account, he was compelled to explain the formation of relative prices for both final goods and resources, because these prices provide the information and the incentives that coordinate the division of labor. Unfortunately, his theory of 'natural' prices contained serious ambiguities and inconsistencies that his classical successors never quite managed to correct satisfactorily. When the science of economics became an academic discipline in the last quarter of the 19th century, the professors finally clarified and straightened out the confused and incoherent 'classical' theory by developing a general equilibrium theory in which everything determines everything else on the basis of interactions among optimising resource owners. This system has proved so attractive, so aesthetically satisfying, that many students of economic theory since the neoclassical reformulation never make it back to the issue of how markets work, the issue that inspired the question of relative prices in the first place. That's why so much of elementary economic theory focuses on the optimisation process rather than the process of exchange. As the drunk said when asked why he was searching for his keys under the street lamp despite the fact that he had lost them somewhere else, 'The light is better here'. Many professional economists would rather shine a sharp clear light on nothing at all than wander in partial darkness.

\section{Rigour vs Plausible Stories}

As mentioned earlier, the dominant culture in the economics profession values rigour above all other virtues. The emphasis on rigour, besides encouraging us to emphasise optimisation over exchange, also prompts us to treat exchange in an overly formal and mechanistic manner. Supply and demand makes up the core of useful economic theory. But if it is to be useful to students in a beginning economics course, supply and demand must be taught as a process rather than as a pair of simultaneous equations. While graphs can be useful aids in teaching supply and demand, they are not useful when they drive out all consideration of actual social transactions. Students don't learn how markets work by learning how to solve simultaneous equations or to manipulate graph lines.

This implies that teachers of introductory economics must leave behind their lust for rigour when they enter the classroom and must learn to be comfortable with approximations, with uncertainty, and with what is coming to be my favourite phrase: plausible stories. We economists are too quick with the definitive answer, which is usually some variation on 'misallocation of resources'. Price controls, agricultural marketing orders, protective tariffs, cartels, restrictive licensing, and a wide variety of government 'interferences' always lead for us to a misallocation of resources. This summary judgment is less instructive and less likely to be incorpo- 
rated into a typical students' understanding than is a plausible story indicating some of the major effects that will probably follow from this or that event.

Take the case of price controls. Should the government impose temporary price controls after a natural disaster, such as a hurricane? It's easy to shift an upward-sloping supply curve to the left along a downward-sloping demand curve and to demonstrate that the quantity demanded will exceed the quantity supplied if the price is not allowed to rise. Typical beginning students, however, will be much less impressed by a gap between the demand curve and the supply curve than by the thought of merchants or landlords profiteering at the expense of poor families. When we tell them that price controls allow scarce goods to be used for purposes less valuable than they would be used for if prices were allowed to rise, they are not likely to be much distressed at the prospect. We have to become concrete and specific.

Ask the students what particular goods are likely to be in very short supply right after a hurricane. Write their suggestions on the board and add some crucial ones that they are not likely to think of. Then take several of them in succession. Electric service will probably have been disrupted by the hurricane. How will that affect the demand for ice? How elastic will the supply curve be in response to the increased demand? If the price is not allowed to rise, how will the ice be rationed among those who are clamouring for it? Is this likely to be a fair allocation? Why is it likely to produce a situation where some obtain more ice than they really have any use for while others go without altogether? Why is the supply likely to be more elastic in the longer run than in the very short run? What role does a rising price play in bringing more ice into an area suffering from extensive electrical outages and how does it play that role? How does a rising price encourage people to economise on ice and thus make more available to others? What are some of the substitutes for ice that people will begin using as ice becomes more expensive? How does a rising price encourage those who can economise most conveniently or at the lowest cost to do so?

Plywood provides an excellent case study on which students can exercise their imaginations in dialogue with one another and the instructor. Rising plywood prices provide immediate and effective signals to suppliers, not only of wood products but also of transportation services, to alter their behaviour quickly and in ways that will relieve the misery of people in the disaster area. Rising prices also tell potential users of plywood that, at least for now, they should postpone less valuable and urger projects - in order to save money, from their perspective, but with the benefit to others of freeing plywood for the mitigation and repair of hurricane damage.

I'm learning not to say 'That's wrong', but to substitute the challenge, 'Tell us a plausible story about that'. My own 'answers' are increasingly presented not as the verdict of science or logic or theory but as a story recommended by its plausibility. Of course, I draw on economic theory to devise and recognise plausible stories. A story will not be plausible if it is inconsistent with the basic assumption of economic theory, which is that all social phenomena emerge from the choices individuals make in response to expected benefits and costs to themselves. While this as- 
sumption gives me no clear answer to any actual question, it does alert me to what I should be looking for. What are the relevant benefits and costs? What actions by which individuals could cause the perceived value of these benefits and costs to change (often through changes in their money prices)? What substitutes are available to demanders and to suppliers? Economic theory also reminds me that it is marginal values that matter and that there are many margins on which individuals can pursue the projects that interest them.

My teaching has been significantly altered in recent years by taking to heart Ronald Coase's trenchant indictment of 'blackboard economics'. We are doing blackboard economics whenever we demonstrate, usually with the aid of a blackboard graph, the non-optimal character of a situation and the Pareto superiority of some alternative arrangement, all without paying any attention to what arrangements real people can actually make and the costs of doing so (Coase, 1988:28-9). Standing at the blackboard seems to confer upon many economists, at least in their own imaginations, such divine attributes as omniscience, impartial benevolence, and omnipotence. They suppose that they are whispering in the ear of a benevolent and all-powerful despot, to employ James Buchanan's telling complaint about this way of doing economics (Buchanan, 1979:145). When we accept the obligation to tell plausible stories, we stop overpowering our students with blackboard proofs that have genuine policy implications only under the wholly unrealistic assumptions that we are holding at the back of our minds.

\section{The Art of Economics}

When we shift to the telling of plausible stories, we also begin to recover the lost art of economics. As David Colander (1992) has reminded those who like to use the positive-normative distinction, the original classification made by John Neville Keynes and quoted by Milton Friedman in his influential 1953 essay on 'The Methodology of Positive Economics' was a three-part one: positive economics, normative economics, and the art of economics. Policy differences among economists are rarely rooted in disagreements either about positive economics or about normative ideals, but in uncertainty about what additional considerations need to be taken into account and how best to do so. Resolving these questions is the task of the art of economics, an art which is indispensable for anyone who wants to apply economics to real world issues.

It is an art that will always leave some important questions unanswered, if for no other reason than that we can never be sure when we act or recommend action that we have taken everything relevant into consideration. One of the unfair ways in which we economists bully our students is by responding to their objections with, 'We're abstracting from that'. Once we recognise that the art of economics plays an indispensable role in any application of economics, and that this art includes the act of deciding what to take into account and what to leave out of account, we confront the obligation to justify any challenged abstraction. Whether we may abstract from a particular ethical, social, or political consideration in recommending a policy becomes a question for discussion as soon as the abstraction is challenged. We can 
ask the challenger to construct a plausible story indicating the relevance of the omitted consideration, and we can construct our own plausible story to suggest its irrelevance. But we may not settle the matter by fiat, as we can legitimately do in a piece of 'pure' rather than applied analysis.

These examples have all been taken from microeconomics; but the teachers of introductory macroeconomics have been no less guilty of teaching familiar techniques rather than illuminating ones. My colleague Charles Nelson has suggested in conversation that introductory macroeconomics is still obsessed with the Great Depression more than half a century after it ended because our legacy of macroeconomic tools contains so many concepts devised to explain equilibrium at less than full employment. It would be hard to find a better example of searching where the light is good instead of where illumination is required. Nonetheless, introductory macroeconomics teachers who fail to lay solid foundations for subsequent ISLM analysis will work under the nagging fear that they are not doing their proper job and that they are courting departmental censure. Their job, as conventionally misunderstood, is not to educate the citizens of a democracy, but to begin preparing students for careers as professional economists.

\section{The Dominance of Academic Departments}

Perhaps we won't be able to free our introductory courses from such disabling presuppositions until undergraduate education itself has been liberated from the dominance of academic departments. Departments at leading universities are oriented to their disciplines, which is probably inevitable so long as teaching staff are rewarded primarily for pushing out the frontiers of knowledge in regions controlled by those disciplines. But is it either necessary or desirable that research-oriented disciplines control the content and delivery of undergraduate education? We cannot realistically expect academicians who are narrowly focused on their research interests to reflect thoughtfully on the requirements of a liberal education, or even to care a great deal about general undergraduate education.

An alternative might be semi-autonomous undergraduate colleges within the research universities. It is not certain that such colleges could in the long run escape capture by the research culture of the disciplines while also maintaining high intellectual standards. But the risk might be worth taking. In the long run, as John Maynard Keynes observed in another context, we are all dead. 
158 Paul Heyne

\section{References}

Buchanan, J. (1979), What Should Economists Do?, Liberty Press, Indianapolis.

Coase, R. (1988), The Firm, the Market, and the Law, University of Chicago Press, Chicago.

Colander, D. (1992), 'The Lost Art of Economics,' Joumal of Economic Perspectives 6(3): 191-4.

Samuelson, P. (1946), 'Lord Keynes and the General Theory', Econometrica 14(3): 187-200.

Smith, A. (1776;1981), An Inquiry into the Nature and Causes of the Wealth of Nations, Liberty Classics, Indianapolis.

I am grateful for the comments of two referees, even though they often failed to deter me from my obdurate course. I also want to thank the Editor for his helpful perspective on the first draft. 